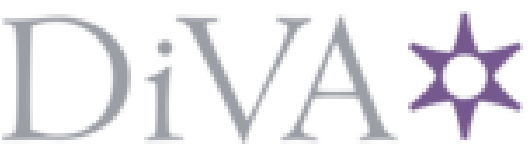

http://www.diva-portal.org

\title{
Postprint
}

This is the accepted version of a paper published in Ancient Philosophy. This paper has been peer-reviewed but does not include the final publisher proof-corrections or journal pagination.

Citation for the original published paper (version of record):

Pettersson, O. [Year unknown!]

Power and Person in Plato's Alcibiades I

Ancient Philosophy

Access to the published version may require subscription.

N.B. When citing this work, cite the original published paper.

Permanent link to this version:

http://urn.kb.se/resolve?urn=urn:nbn:se:uu:diva-423883 


\section{Power and Person in Plato's Alcibiades I}

\section{Olof Pettersson}

The first Alcibiades establishes an important link between the private and the public. In order to get the power-craving Alcibiades (124b1-9) to turn inwards, Socrates argues that any ambition to acquire political influence is conditioned by knowledge of the self. ${ }^{1}$ As it turns out, however, this self is not easy to acquire knowledge of, because it does not involve any person. It does not pertain to looks, stature, natural disposition, background, merit, position, wealth, skill, profession or whatever one might say that could help identify a particular somebody (104a1-c1, 118b1-c2, 119b5-c1, and 129b1-131d8). And yet, it is not without reasons that the dialogue is framed as a conversation between two of Athens' most infamous persons. In the end, Socrates is also less confident than at the outset. Having managed to identify the true nature of the self as the soul, having shown that the soul is divine, and, in effect, having also managed to successfully persuade Alcibiades to start caring for his self and its virtue (135c10-d11, cf. 105d5-e6), Socrates nevertheless concludes by qualifying the force of these results. 'I should like to believe that you will persevere, but I'm afraid - not because I distrust your nature, but because I know how powerful

\footnotetext{
This text had many debts. It owes thanks to Nicholas D. Smith, whose keen eyes spotted many mistakes; to Ursula Coope, who always makes me to think more about the influence of the Neo-Platonists; to Pauliina Remes, who cannot avoid looking beyond the real; to M.M. McCabe and to the learned audience of the Alcibiades I Revisited conference, at the Classics Department in Cambridge (UK), in September 2018, for invaluable comments and critique.
}

\footnotetext{
${ }^{1}$ Henceforth I will refer to the first Alcibiades as the Alcibiades. For discussion of the political underpinnings of selfknowledge in the dialogue, see, e.g., Smith 2004, 102.
} 
the city is - I'm afraid it might get the better of both me and you' (135e6-8). ${ }^{2}$ As we know, it certainly did. ${ }^{3}$ But why, then, encourage the project?

As I shall argue, the answer lies in the failure. The dialogue could have been about, other, more successful persons. But that would have given the wrong impression. The dialogue is not written to be a recipe for political power. It is not meant to show that political influence is the result of self-knowledge. There are in fact reasons to doubt that it is designed to show what selfknowledge is at all. The hypothesis that I would like to try out, instead, is that the main purpose of the Alcibiades is to draw a line, to assess the limits of human knowledge and to help the reader understand that however much we would like to leave the drama behind, we cannot get rid of the persons involved.

My argument has three parts. In part one, I draw on Socrates' discussion of selfhood and use to argue that the self, understood as soul, is dissociated, not only from the body and from the soul-body complex, but also from $\lambda$ ó ${ }^{\circ}$, understood as language and discursive reasoning. In part two, I assess what this dissociation implies and consider one promising and influential interpretation, the so-called theocentric view. According to this view, Socrates' notion of the self is to be 'identified with God' (Johnson 1999, 3). I argue that this view is promising, because it implies a non-linguistic understanding of the self, but also insufficient. First, it is insufficient

\footnotetext{
${ }^{2}$ Translation by Hutchinson, in Cooper 1997. The term for 'get the better of' is $\kappa \rho \alpha \tau \varepsilon \tilde{v}$. The Greek text I am using is Denyer's from 2001.

3 The presumption here, of course, is that even if Alcibiades became a famous and efficient military leader, his life was a failure, as evidenced by his inability to resist the urge to make war, deceive, lampoon the religious mysteries, double-cross his friends, steal and betray his allies. For a similar point of view and discussion thereof, see Denyer 2001, esp.1-3 \& 7-8. That the city got the better also of Socrates, is well documented in Plato's Apology.
} 
because it fails to acknowledge that Socrates' notion of divine selfhood must nevertheless be mediated by human, and thus non-divine, language; second, because identifying the self with divinity makes humans into gods; and third, because the dramatic framing of the dialogue may seem to disqualify the theory that the self is to be 'identified with God' in virtue of a failure to establish viable conditions for human success and political prosperity. In part three, I outline an

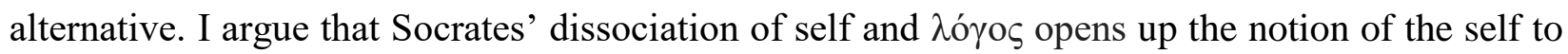
an implicit distinction between an ideal and a real understanding. While the ideal self corresponds to Socrates' explicit arguments and to his attempt to reduce the self to the divine soul, the real self corresponds to the dialogue's dramatic framework, to the persons involved and to the language they use. Evidenced by Socrates' socio-political terminology in his efforts to identify and describe the divinity of the self, I suggest that Plato wants to shows that the link between selfhood and politics is important and that the view of the divine self presented by Socrates must be understood in light of how it is presented. Plato makes Socrates talk about an impersonal self. Socrates speaks about the self as divine and he dissociates human $\lambda$ ó $\gamma$ os from it. But this, of course, does not make his own words divine. As the rest of us, Socrates is bound to human concepts and terminology. As this goes to show, the ideal self is conditioned by the real. However much we want things to be different, divine selfhood and virtue cannot escape the fallible, personal and socio-political normativity inherent in human language and practice, or so I shall argue.

\section{The Silence of the Soul}


However we are to understand the doubts that have been raised about the authenticity of the first Alcibiades, it may seem as if the author anticipated them by setting a philosophical trap. ${ }^{4}$ The downplay of the importance of individual personality is not only made essential to Socrates' attempt to persuade Alcibiades that he needs to get to know his self. If Socrates' argument has any truth to it, there are also good reasons to let the question of authenticity go and to focus instead on what the dialogue has to say about our ideal and divine selves. If we can allow ourselves to be persuaded by the dialogue to think that its message is important and philosophically relevant, we are however already caught. Because as soon as we let go of the importance of personal identity, and take the dialogue's message to our hearts, we should also soon realize that the source of that imperative undermines its own message. The self that the text puts on offer is only accessible through a medium that cannot represent it. If we trust what we are reading, we should not care about who wrote it and who speaks in it, and yet the dialogue's dramatic framing makes this impossible. In the Alcibiades, there are no voices from nowhere. As such, it seems, the medium inhibits the message. Even if it tells us to, we cannot read the Alcibiades without paying attention to its names. Indeed, the fate of the dialogue still stands and falls with the personal authority of Plato. Perhaps David Johnson's diagnosis is right, though: '[It is a] sign of the modern faith in the significance of the unique personal self that scholars have cared more about the identity of the author of the Alcibiades than about what the dialogue has to say about personal identity' (Johnson 1999, 1). According to Johnson, there are reasons to read the Alcibiades even if Plato did not write it, because 'the dialogue's claim that the self is something objective and impersonal ought to make us think twice before ignoring the Alcibiades simply because we cannot be sure that Plato wrote it'

\footnotetext{
${ }^{4}$ For discussion about the authenticity of the first Alcibiades, see, e.g., Smith 2004 or Remes 2013.
} 
(Johnson 1999, 1). ${ }^{5}$ More generally speaking, Plato may very well have shared this point of view. Even if he did not write the Alcibiades, he didn't consider his personal authority so important that he made himself the main character in the dialogues, as Aristotle supposedly did (Denyer 2001, 4). Despite the fact that Platonic anonymity may perhaps have caused more headaches than intended, the Alcibiades also offers us reasons to respect it. Socrates' argument to this end is familiar. The self is reduced to the soul. The self is not the body nor what belongs to it and it cannot be identified with an individual person. And yet, this argument contains a peculiar detail that may both upset the conclusion it implies - that the self is not an individual person - and in this way reconcile the argument with the dialogue's larger dramatic framework: The self is dissociated from $\lambda$ ó $\gamma$ os, that is, from discursive reasoning or language. Why does this matter?

Socrates' point is perhaps made most explicit at around 130e2-5. At this stage in the argument, Socrates has already showed Alcibiades that the body cannot be the self because the user is not the same as the thing used. The argument to this end started out at around 129b1-3, as a discussion of the use of $\lambda$ ó $\gamma o \varsigma$, and it is to this point that Socrates now returns.

That's just what we were saying a little while ago - that Socrates converses $(\delta 1 \alpha \lambda \varepsilon ́ \gamma \varepsilon \tau \alpha \imath)$ with Alcibiades not by saying words ( $\lambda$ ó $\left.\varphi_{\llcorner} \chi \rho \omega ́ \mu \varepsilon v o\right)$ to his face, apparently, but by addressing his words to Alcibiades, in other words, to his soul (130e2-5). ${ }^{6}$

\footnotetext{
${ }^{5}$ My italics.

${ }^{6}$ Lamb's translation from 1927, puts more emphasis on the fact that Socrates is talking about using words: 'Well, that

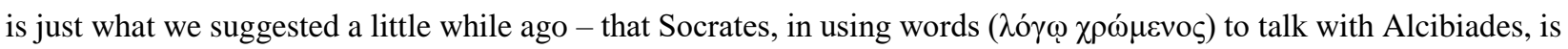

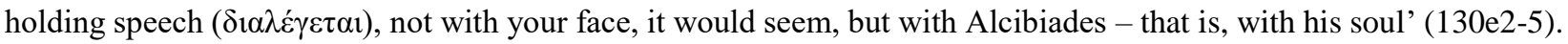


Socrates' point is twofold. On the one hand, he wants to check that Alcibiades still agrees that he is not his body. On the other, he also makes this point by reestablishing that $\lambda$ ófos, however we understand it, just like the body, is something that is used by the soul and that it, as such, is something that the soul cannot be identified with. Just as we cannot understand the soul in terms of the body, except as its user, we cannot understand the self in terms of $\lambda$ ó $\gamma o \zeta$, except as its user.

Socrates' initial argument to this end had a somewhat different agenda, but the conclusion is the same. In order to dismantle Alcibiades' person, Socrates asked who Alcibiades was speaking

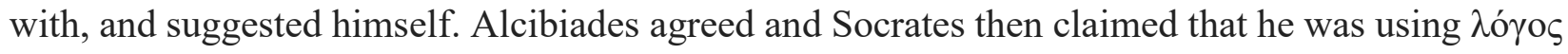

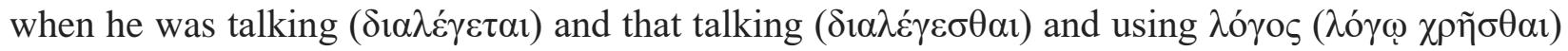
is the same $(129 \mathrm{c} 2-3)$. Alcibiades accepted also this $(129 \mathrm{c} 4)$. When Socrates then went on to

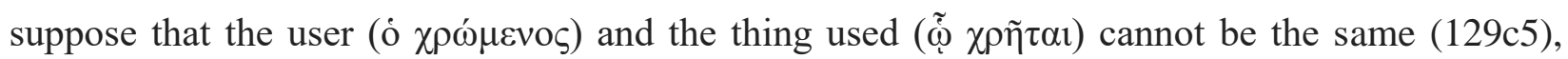
Alcibiades was however more perplexed (129c6).

To explain, Socrates used three examples: shoes, harps and bodies. In all these cases, we learn, it is possible to dissociate the user from whatever is being used. And in all these cases, just as in the case of $\lambda$ ó $\gamma$ os, there are important differences. The harper is not his harp. The shoemaker is not his tools. The soul is not the body. And the self is not whatever it says. The two, Socrates

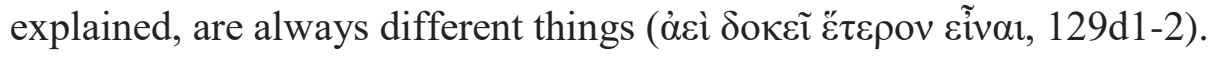

However strange this conclusion may seem, it is not controversial, although perhaps understudied. Neither Pauliina Remes nor David Johnson, for example, deny that Socrates concludes that the soul is not what it uses and that this includes $\lambda$ óros. Both do however try to explain away this fact in various ways.

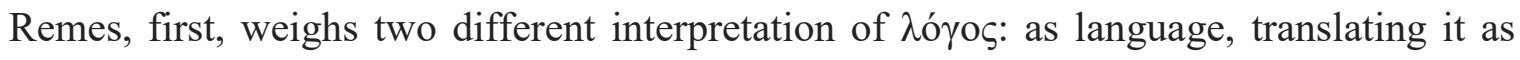
'words' or 'talk'; and as rational deliberation, translating it as 'thought' or 'reason' (Remes 2013, 283). From the point of view of language, she has no problem of acknowledging the distinction 
between the user and the used. Language, as she accurately points out, is from Socrates' point of view a social affair. If there is anything that the multitude knows, it is Greek (111a1-4). 'Taking logos in this simple sense', she writes, 'would imply that there is a distinction between what you yourself are and the language you have learned in your community. The self would, then, be a thing above words, that part which uses them' (Remes 2013, 283).

From the point of view of reason, however, Remes is less forbearing. In trying to avoid what may very well be a 'threatening duplicity' she claims that there are reasons to think that the soul does not stand above reason, as in the case of language (Remes 2013, 284). But this, it seems, begs the question. We cannot, at least not at this point in the dialogue, presume that we know that the soul, in its core, is another form of rational deliberation, even if we know that it eventually will be described in terms of its ideal reflection as divine wisdom. Further, even if $\lambda$ ó $\gamma$ o - in some cosmic Heracleitan sense, as Remes points out - would be able to put the soul in contact with a higher-order rational force, that would not make the soul the same as what it is in contact with. As we shall see, the writer may have had other reasons to make Socrates describe the soul in terms of its divine nature, reasons that would justify the dissociation of soul and $\lambda$ ó $\gamma o s$. But before I turn to this, I would first like to consider another type of worry, raised by Johnson.

Johnson's point is not that Socrates does not make the distinction between soul and $\lambda$ ó $\gamma$ os, but that the whole argument is insufficient, and that Socrates knows this. Johnson also suggests that Socrates soon drops the whole matter (Johnson 1999, 5-6). To explain, Johnson introduces two examples: ruling and knowing. The first example is in the text. The second is interpolated. The point is, however, the same. If the user and the thing used need to be separate, and ruling and knowing are examples of use, self-rule and self-knowledge would not be possible. If Johnson is right, Socrates has good reasons to drop the whole argument and use a better one. In addition, one might also ask why Socrates at this point in the dialogue hesitates. As pointed out by Johnson 
$(1999,6)$, Socrates claims that their argument is moderate ( $\mu \varepsilon \dot{\tau} \rho\llcorner\varsigma$, 130c8) and reasonable

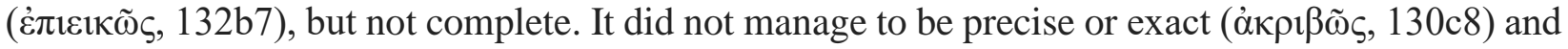
this may be taken to indicate that the argument up until this point had only been about what 'an individual self is, instead of what 'itself' is', as Socrates puts it (130d5-6). ${ }^{7}$

To get a better grip of what is at stake here, two considerations are worthwhile. On the one hand, Socrates certainly develops the investigation as the conversation goes on, but that does not mean that he starts from scratch or dismisses what they have already discovered. Besides the discussion about use and $\lambda$ ó $\gamma \varsigma_{\varsigma}$, Socrates offers no other arguments for the conclusion that the self is the soul. If Johnson is right, there should be at least one more argument that could carry the load. As the text stands, however, we have nothing of the sort. Insofar as it cannot just be presumed that the self is the soul, the lack of further discussion of this matter indicates that although the useargument may not be sufficient to show exactly what the 'itself', in the expression 'the self itself', is, what they have discovered so far is certainly necessary for what shall come. Indeed, Socrates does not just stop talking about the use of $\lambda$ óyo $\varsigma$ and about what belongs to the soul after he has nuanced the quality of their argument. ${ }^{8}$ Instead he goes on and makes the same point again: 'So the right way of looking at it [despite the imprecise nature of the argument] is that when you and I talk

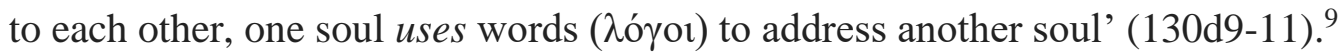

\footnotetext{
${ }^{7}$ I owe this remark to the anonymous referee.

${ }^{8}$ In the pursuing discussion, Socrates also maintains the related talk about what belongs to the soul without being the same as it. In the contested passage 133c8-17, Socrates also discusses how best to use a mirror. For discussion, see Remes 2013, 292.

${ }^{9}$ My italics.
} 
On the other hand, and even if Johnson is wrong to dismiss the argument as unnecessary or supplemented later, we may still need to explain why Socrates feels the need to qualify what they have been talking about. Socrates' point at 130d5-6 goes back to 129b1-3. There, Socrates

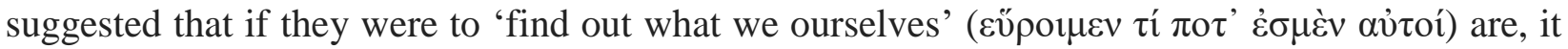
might be a good idea to first understand what the 'itself' in the expression 'we ourselves' actually means, on its own, or in itself ( $\alpha$ $\tau$ ò $\tau \alpha \hat{\tau} \tau o ́, 129 b 1$ ). When Socrates and Alcibiades now return to this point, at 130d5-6, they had followed one line of argument that began as an examination of the nature of conversation and ended up concluding that the self is the soul. But according to Socrates this was not exactly what he suggested at 129b1-3. What Socrates suggested was that they examine what something in general is, if it is something in itself. He suggested that they should examine the nature of self-identity in general, in itself, and not in relation to some particular kind or type, such as a soul. So, when Socrates eventually comes to claim that they skipped over a longer and more difficult discussion (130c8-d7), he is not suggesting that there is another or better way to show that the self is soul (cf. 130c5-6). On the contrary, since 'nothing about us has more authority than the

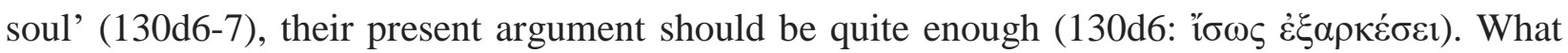

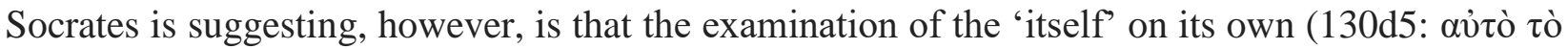
$\alpha \cup ่ \tau o ́)$, requires a different kind of examination than an inquiry into the nature of the 'itself' as it

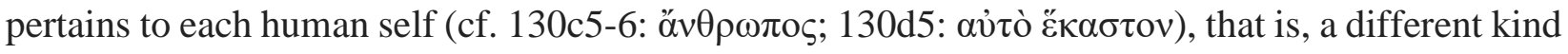
of examination than an inquiry into the nature of the soul. ${ }^{10}$ In the argument that follows, culminating perhaps with the description of the soul as divine (133c1-2), it is also assumed that they have already proven that the self they are talking about is the soul and that they are talking

\footnotetext{
${ }^{10}$ In the Sophist (esp. 253a4-259b6), Plato does something that might answer to this call in examining the nature of 'the same' and its relation to other forms or kinds. For discussion, see Pettersson 2018.
} 
about this self in the sense of agency (be it divine or not), and not about the self, or the 'itself', in the sense that a (soulless) word or a though can be 'itself' by being the same as itself. All of this indicates that Socrates is aware of the fact that the matter of selfhood is entangled with more general philosophical considerations about self-identity and self-predication, but for his present purposes with Alcibiades, and for the inquiry into the self as soul, an investigation of these matters would take them too far off topic.

Another connected reason for why Johnson thinks that the use-argument is incomplete, and dismissed by Socrates, is that he thinks that Socrates talks about using the soul in a similar fashion as he talks about using $\lambda$ ó $\gamma$ os $(1999,5)$. Johnson refers to $130 \mathrm{~d} 9-11 .{ }^{11}$ But, at least if we go on Denyer's assessment, the participle here, $\chi \rho \omega \mu \varepsilon$ vov, is to be taken with the $\lambda$ ó $\gamma o \varsigma$ and not with the

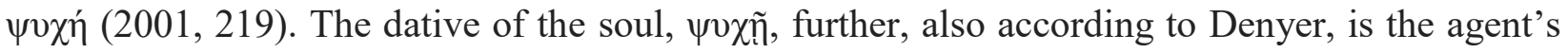
and not the instrument's. ${ }^{12}$ So, at least if Denyer is correct, there is nothing in this passage that indicates that the soul is supposed to use the soul or that the argument is incomplete.

\section{Is the Self Divine?}

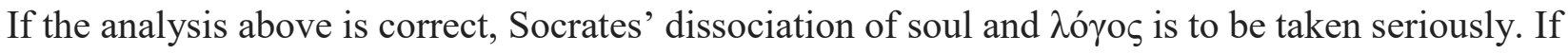
Remes is right, which I think she is, there are nonetheless also reasons to consider Socrates' notion of soul in rational terms. But how, then, are we supposed to understand what Socrates means to

\footnotetext{
11 'And it is [then] proper to take the view that you and I are conversing with each other, while we make use of the

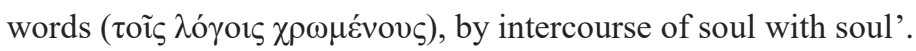

12 Denyer 2001, 219, refers to similar uses in Tht. 184d, Grg. 523e \& Phd. 66e.
} 
dissociate the soul from? Judging by what Plato has to say about $\lambda$ ó $\gamma$ o possible to identify a candidate for what we might be dealing with.

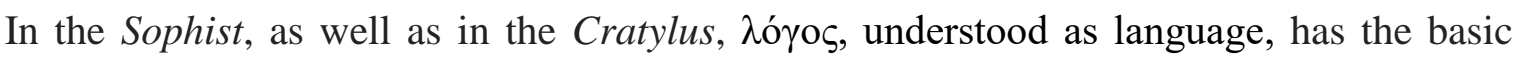
structure of being a subject-object compound. For some collection of words to be a $\lambda$ ó $\gamma$ os, something needs to be said about something. From the Sophist we learn that a $\lambda$ ó $\gamma$ os is always a weaving together of nouns (óvó $\mu \alpha \tau \alpha)$ and verbs ( $\rho \eta ́ \mu \alpha \tau \alpha, 262 b 9-c 7)$ and it is always about something (262e5-6). This also means that a $\lambda o ́ \gamma o \varsigma$, as a minimum, always has some quality ( $\pi$ oióv, $262 \mathrm{e} 8$ ), in the sense that it is true if it answers to the reality it is about, and false if it does not (263c9-11). ${ }^{13}$ In the Cratylus, the point is similar. A $\lambda$ ó $\gamma$ o $\varsigma$ cannot be a mere list of names, or verbs, or some mere exclamation or noise, but must, at a minimum, be a combination of verbs ( $\dot{\rho} \eta \mu \alpha \alpha)$ and nouns (óvó $\mu \alpha \tau \alpha)$ and this combination should be able to succeed or fail to be true (431a6-c2). ${ }^{14}$

On the most minimalistic interpretation of these passages, then, a $\lambda$ ó $\gamma$ $\varsigma$ is a number of words that in combination are about a state of affairs where something - call it the subject - is said to suffer or do something - call it the object. What I call the object and the subject here, can, of course, consist in more than one component. But the object does in any case represent some set of circumstances that are predicated about the subject. ${ }^{15}$ In a $\lambda$ ó $\gamma$ os, then, as in dialectic, the active operation is, on the one hand, a division of some functioning whole into parts and, on the other hand, a reunification of these parts. While there is nothing that necessitates that the subject is different in nature from the object - both can be blue or multiform or pure being - the point is that

\footnotetext{
${ }^{13}$ For discussion, see Brisson 1998, esp. 93f.

${ }^{14}$ A $\lambda$ ó $\gamma o \zeta$ is neither a list of names, as 'lion, stag, horse', nor a list of activities, as 'walk, runs, sleeps'.

${ }^{15}$ In the Cratylus, Sedley 2003, 123n1 and 162-4, translates $\dot{\rho} \tilde{\eta} \mu \alpha$ with 'description' to encompass the fact that a $\dot{\rho} \tilde{\eta} \mu \alpha$ can consist of more than one word. As such, he suggests, $\lambda \dot{\varepsilon} \gamma \varepsilon ı v$ functions as its verbal counterpart.
} 
a $\lambda$ ó $\gamma$ os always operates with a difference that is not present in what it is about. In order to say something about something, and thus to generate a $\lambda$ ó $\gamma$ os, it is not only necessary to identify a subject, that is, by disjoining and separating it off from the event as a whole. It is also the difference thus established that generates the gap that the linguistic predication and the ascription of the object to the subject is a bridge over. The difference, then, between an event and the $\lambda$ ó $\gamma$ o $\varsigma$ that describes it, is that the $\lambda$ ó ${ }_{0} \varsigma$ brings with it a difference that is not there in the event itself.

This analysis, I claim, pertains to the criteria Socrates sets up for the self. If we add these linguistic restraints to his dissociation of soul and $\lambda$ ó $\gamma \circ \varsigma$, we also get a somewhat different picture of the self than is often acknowledged. The self is not the body nor its tools. But it is not the $\lambda$ ó $\gamma \circ \varsigma$ it uses either. This means that whatever the self is, we should try to understand it in a way that avoids drawing on the structure of $\lambda$ ó $\gamma$ os. Just as the soul conditions the use of the body, and cannot be described in terms of it, the soul conditions the use of $\lambda$ ó $\gamma \circ \varsigma$, and should perhaps not be described in terms of it. This does of course not preclude $\lambda$ ó $\gamma$ os itself from being more than a collection of declarative statements, but it does mean that $\lambda$ ó $\gamma \circ \varsigma$, at its most basic level, seems to have a different structure than the self.

If my brief analysis of this has any bearing, and the true self is not to be identified with the $\lambda$ óyos it uses, this also implies that we should avoid understanding the self in terms of the subjectobject structure that constitute $\lambda$ ó $\gamma$ o $\zeta$ under this description. The self, instead, is what makes such a structure conceivable, perhaps, in the sense that it is the self that can establish the necessary differences and use them for whatever communicative purposes it intends. However rational the self is supposed to be, then, our interpretive options seem to be limited by the restraints imposed by the use-argument and the dissociation of self and $\lambda$ ó $\gamma o \varsigma$.

One influential interpretation of the relevant passages that may seem to be able to accommodate these considerations and explain how they square with the dialogue's overall purpose 
is the so-called theocentric view. ${ }^{16}$ According to this view, the self is to be 'identified with God' (Johnson 1999, 3). The self's divinity is to be taken as a direct consequences of Socrates' argument and has to many, not the least to some central Neo-Platonists, seemed to be beyond reasonable doubt. If this would be true, the self should also be able to transcend the object-subject difference (outlined above) and be rational in way that does not transgress the defined restrains. Let us look at the evidence.

On the one hand, Socrates' claim that the soul is divine is quite explicit, even if we leave out the passages supposedly added by Eusebius. ${ }^{17}$ If the self is like an eye, it needs some mirror to look at to see itself, because an eye cannot see itself directly. The best of all such mirrors is another's eye and in that eye there is a particularly clear spot where the true self is best reflected. In the pupil, the self can see itself as it truly is (133a1-12). When it looks in this mirror it will see that the virtue of the soul is wisdom ( $\left.\sigma \circ \varphi i^{\prime} \alpha\right)$. This experience will also reveal that no other part of

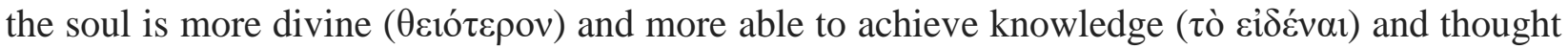
( $\varphi \rho \circ v \varepsilon \tilde{v})$.

On the other hand, Socrates also spells this point out in terms of the relation between selfknowledge and what has been taken to be the dialogue's overall purpose: to explain how selfknowledge conditions power and political influence. Whoever looks at what is most divine in the soul, we learn, will come to acquire the best knowledge of himself. This knowledge, further, conditions knowledge of one's own belongings and, in effect, also of others' belongings. One cannot, we learn, know what belongs to others if one does not know what belongs to oneself (133d1-134a1). And since all affairs of the state and its economy involves knowledge about what

\footnotetext{
${ }^{16}$ As developed by Johnson 1999. Cf. Annas 1985. For discussion and references, see Remes 2013.

${ }^{17}$ For discussion, see Remes 2013, 292ff.
} 
belongs to others, self-knowledge condition the ability to handle the affairs of the state and its economy (134e12). As such, however, Socrates also takes the argument to work the other way around. If one manages to see one's true self and its divine nature, one should not only become happy, one will apparently also acquire all tools and skills necessary to handle the affairs of the state, administer its economy and impose virtue on its citizens (133e10-134c12).

Insofar as we interpret these passages in theocentric terms, Socrates' notion of the divine self should not only be able to transcend the subject-object difference (outlined above) by being endowed with divine rationality and thus by being above the basic subject-object structure of human $\lambda$ óyos. On this view, the overall purpose of the dialogue should also be to taken to show how Socrates' notion of the divine self conditions power and influence. There are however a number of reasons to resist this line of interpretation.

First, there are several general reasons. As argued by Remes, to consider God the end of a search for the self, does not only defy the cause of that search. It is also odd to set up criteria for a particular agent or subject, if the purpose nevertheless is to identify an entity that is external to it (Remes 2013, 289). In addition, Remes also reminds us that we should not forget that divinity in ancient philosophy, in any case, served a much smaller role than later in the history of philosophy. Even if Socrates does talk about the soul in terms of its divinity, that might not mean more than that selfhood is aspirational (294). ${ }^{18}$ 'Selfhood', Remes explains, 'comes in degrees and is tied to normative ends' (294). Such a notion of selfhood would be perfectly compatible with an impersonal and objective notion of the self, as outlined by some proponent of the theocentric view (e.g. Johnson 1999) and sits well with Socrates' further argument connecting selfhood with virtue and wisdom.

\footnotetext{
18 For discussion, see McCabe 1994, Ch.9, Pradeau 1999, 133n10 or Gerson 2002, 9-10.
} 
Second, it is not uncommon to imagine what a true self, in a divine or aspirational sense, could be. Socrates' argument also answers to such an intuition and is made to seem reasonable. In truth we are, or should be, the best we can. It is perfection and, in the ethical realm, virtue, that define our essence. The only tools we have available to understand, identify and spell this perfection out, however, are not themselves divine, or, if I am right, not really a part of the true self at all. If Socrates' talk about eyes, mirrors and vision is an image of a conversation, as he certainly seems to suggest (132d5-8), the medium of beholding the divine is discursive. But there is nothing in what he says that indicates that this medium itself is divine. On the contrary, and as a precaution, perhaps, Socrates initiates the argument that will end up identifying the self as divine by separating $\lambda$ ó $\gamma$ os off. In perfect line, then, with the dramatic limitations that the dialogue puts on the selfknowledge it proposes, the medium of the message defies its cause.

A third reason to entertain alternatives to the theocentric interpretation is that the divine self is not really accessible in the way proposed. Evidence of this can be found in Socrates' vocabulary.

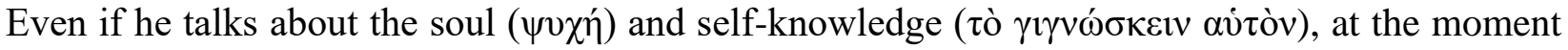
of conception (133c18), the argumentative residue should not be ignored. In the whole proceeding argument, and especially in that part of the argument that establishes that the self is the soul, Socrates uses the word $\alpha 2 v \theta \rho \omega \pi \mathrm{s}$ to denote the self $(129 \mathrm{e} 10,130 \mathrm{a} 7,130 \mathrm{~b} 9,130 \mathrm{c} 2)$. For example, in claiming that acquiring knowledge of the self is not an easy task and that to follow the Delphic imperative is perhaps not for all, the inquiry is clearly pursued in terms of the human self. After some talk about $\lambda$ ó $\varsigma_{\varsigma}$ and use, discussed above, Socrates eventually also concludes by asking if Alcibiades 'require any clearer proof [than this] that the soul is man ( $\dot{\eta} \psi v \chi \eta \dot{~ \varepsilon ́ \sigma \tau \iota v ~ o ́ v ~} \theta \rho \omega \pi \circ \varsigma)$ ?' (130c5-6). Alcibiades answers no. In what follows there is nothing that could be said to resist this conclusion, except perhaps, then, when Socrates comes to the argument about divine mirrors; for if the earlier identification of self and soul is true, and the self we are talking about is the human 
being, the upshot would be nothing less than that man is god. Socrates is of course aware of the impiety of such a claim. Even if he does suggest that his mission is divine and that his approach to Alcibiades has divine sanction (cf. 103a4-6 and 135d6), he makes sure not to identify himself with the divine voice that helps and guides him (cf. 105d6-e6). Socrates knows that he is no god.

A fourth and final reason to resist a theocentric interpretation, as we have also seen above, is dramatic. The dialogue is not a treatise and it does not offer any declarative definition of the features of a divine self. Instead, we are offered a conversation between persons, and between persons for whom personality matters. Indeed, insofar as Socrates is right and knowledge of the self should amount to the ability to rule oneself and the city, both Socrates and Alcibiades should have been in the best of positions to acquire this knowledge and to care for their selves in a way that would make them successful citizens and stable political leaders. As we know, this did not happen. Supposedly, this is an important part of what the dramatic framing of the dialogue is meant to communicate. The drama indicates that the divine self is perhaps not as easily accessible as the theocentric point of view may seem to suggest.

\section{Real and Ideal Selves}

Insofar as the preceding analysis has any plausibility, we have cause to resist a theocentric interpretation and to consider alternatives. My contribution to developing such an alternative would be to insist that we look closer at how the notion of the divine self correlates to the dramatic personalities in the dialogue and to the way they use a socio-political terminology.

As we shall see, there are reasons to suspect that divine virtue and selfhood can at best be understood as socio-political normativity when described from the point of view of a human. Even if Socrates suggests that he has divine help, he is, of course, not a god. Socrates' failure to turn his 
words into deeds - to win the city over and make it virtuous - also indicates that the writer of the dialogue may have wanted to show what Socrates does not say. On this view, there is also an important correlation between Alcibiades' and Socrates' failures to embody what is divine and the socio-political conditions of Socrates' notion of selfhood. To my knowledge, this has not been acknowledged in the scholarly literature. Although the socio-political terminology Socrates is using is well known, we have reason to look a little bit closer at this and reconsider to what extent Socrates' notion of the divine self is conditioned by socio-political underpinnings.

First, it is well known that Socrates' notion of selfhood is described in terms of $\sigma \omega \varphi \rho о \sigma u ́ v \eta$ $(131 b 4,133 c 18,134 c 12)$. According to Remes, $\sigma \omega \varphi \rho \circ \sigma v ́ v \eta$ is in general a virtue that 'emphasized a particular dimension of selfhood, [namely] the ethical subject, or the person living in society'

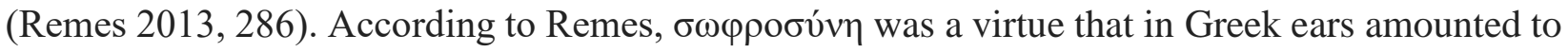
a self-assessment of how one was supposed to behave 'in relation to others, contextually' (Remes 2013, 286). The norms this puts at stake, are thus not ideal, in the sense that they come as decrees from above, or from within, but they are instead 'dependent on the culture [one] lives in and its shared values' (286).

A second factor that matters, and that also indicates that Socrates' notion of selfhood, however divine, cannot escape its dependence on socio-political normativity, concerns how the notion of self-knowledge was understood in a more mundane context. As pointed out by both Julia Annas and Remes, self-knowledge, in a more general and non-platonic context was not understood as some kind of individual achievement or success, but in terms of being able to acknowledge one's position in society. This involved knowledge about one's social role, station and function in the community (Annas 1985, 121ff). ${ }^{19}$ As Annas points out, Socrates does for example blame

\footnotetext{
${ }^{19}$ For discussion, see Gordon 2003, 21.
} 
Alcibiades for his ignorance about Sparta and Persia because it is expected for someone of his position in society to know such things (Annas 1985, 122).

A third and perhaps more concrete reasons to think that Socrates' notion of the divine self, at the end, is conditioned by a socio-political framework, pertains, again, to the discussion about use. In the argument to establish that the self is the soul, the self is described as a user (131c4). Just as a cobbler uses knives, a human being uses language and body. In the way that the cobbler is thus defined by the use of his tools, a human seems to be possible to define by reference to her ability to use language and the body. That, of course, is not what happens. Neither cobblers nor humans are ascribed any knowledge of themselves in terms of what they do or use. This, of course, seems paradoxical, but can perhaps be explained. It is only as a human that the cobbler cannot be said to know himself in virtue of his knowledge of cobblery. Analogously, it is only as an ideal or divine self, that a human cannot be said to know herself in virtue of her knowledge about the use of language and body. In this sense, Socrates seems to operate with an implicit distinction between an ideal and a real self. While the first is divine and abstract, in the sense that its nature lies in its virtue and is an aspirational notion, the second is human and answers to the actual persons present in the discussion. Insofar as there are only actual persons present in the discussion, there are however also reasons to think that Socrates' assessment of the ideal virtues of the soul are only accessible in terms of the real. Even if the soul's knowledge of itself is ideally disconnected from language and body, in all practicality and in terms of the conditions for political influence, the self must nevertheless be judged as a user. Even if an ideal self can be though to be beyond any finitude, the real self is always situated within it. ${ }^{20}$ To repeat the point from above, in truth we are the best we can be, but the tools we have available to understand, identify and spell this perfection out are

\footnotetext{
${ }^{20}$ I owe parts of this remark to Ron Polansky.
} 
not ideal. We need the body and our language to talk about what is beyond body and language. We need to use them. But what, then, does that mean?

One commentator has argued that we need in this context to acknowledge the operating term here: $\chi \rho \tilde{\eta} \sigma \theta \alpha$. Both in- and outside a philosophical context, the term is common. In most contexts we can also note that it connotes a set of well-known socio-political normative values (Foucault 2005, 56). There are many examples, but for my present purposes, two will do: Horses and gods. When a Greek used a horse, this was not just riding it, but the practice included many rules also involving the social aspects of how to treat this particular animal. Similarly, the Greeks also used gods. Clearly not denoting exploitation, or even just plain use (as we have it), the use of the gods involved a behavioral framework restrained and defined by correct practice and in showing proper reverence (Foucault 2005, 55). ${ }^{21}$ When Socrates uses the term use to define what it means to be a human self, he clearly draws on this practice and this tradition. But instead of acknowledging the term's socio-political origins, as when applied to human deeds and in the use of the body, he instead raises the normative force of the rules and practices in question to a superhuman level.

The problem with this move, of course, even if we call the result divine, is that the same structural foundation will remain. Even if the human self should ideally be understood in terms of its virtues, and not in terms of how it uses language and the body, it is the norms involved in the latter practice that at the end of the day conditions our knowledge of the former. When the soul uses language and the body, it uses them in accordance with a number of established socio-political norms and not according to some higher divine standard. Since we have only indirect access to the divine, however - by examining it and by reasoning our way forth - it is only in terms of these

\footnotetext{
21 Alcibiades obviously did not always acknowledge this practice. For discussion, see Denyer 2001, 2.
} 
practices, the norms they embody and the vocabulary they involve, that we can talk about what is ideal at all.

A fourth and final reason to think that Socrates' notion of the ideal self is conditioned by its real or socio-political counterpart pertains to the dialogue's framing. As we know, the dialogue both starts and ends on a political note. It begins with Socrates' summary of Alcibiades' political ambitions and it ends with his statement that even if he hopes that Alcibiades will be helped by the discussion, he is afraid that it will not, and the that city will in any case outwit them both (135e68). This, taken together with Socrates' attempt to motivate Alcibiades to pay attention by promising him power, and his probing examination of Alcibiades' political inclinations at the outset (124e1130c6), seems to indicate that the discussion really never departs from the realm of human affairs, even when it may seem so.

Taken together, these four reasons also confirm the suggestion made above. However much we strive to understand what we should and could be, neither we nor Socrates have access to the divine, and in effect, to our true or ideal selves. Our language, just as our embodied nature, makes our position badly equipped to identify and describe what we could imagine perfect virtue and selfhood to be. When we nevertheless try, as we are inclined to do, we are forced to use an anthropocentric and socio-political vocabulary. This does not make it true, but it may be a truth about the human condition.

\section{Conclusion}

The first Alcibiades is a vexed and complex drama. Its establishes an important link between selfhood and politics. But this link is not established in the way we might have expected it to be. Even if Socrates is made to argue that all political aspirations need to be based on self-knowledge, 
the notion of selfhood he ends up defending is conditioned in a way that makes it impossible to speak about without violating these conditions. Socrates talks about what is divine, and he dissociates the self from human $\lambda$ ó $\gamma$ os. But he has no divine vocabulary at hand and he is forced to use what is available. ${ }^{22}$ In this light, the conclusion Socrates draws is perhaps not as strange as it might at first appear. We can imagine Socrates and Alcibiades looking into each other's eyes and hoping. But the city got the best of them both. Socrates did not manage to persuade Athens of his virtues and was killed. And Alcibiades, perhaps even inspired by Socrates' dangerous eulogy of the Spartan and Persian societies, never really understood where he belonged. History places Alcibiades besides Socrates: as another failure, as another corrupted youth. This we deem a mistake. But perhaps it is not. Perhaps Socrates was right all along. Only when we realize what we truly are, can we understand how philosophy and politics are intertwined. Philosophy is not a matter of managing success, but of learning how to handle failure.

\section{Department of Philosophy, Uppsala University}

\footnotetext{
${ }^{22}$ In the Cratylus, Socrates offers some examples of such a divine vocabulary, as taught by Homer, e.g. at 391d8: 'The river that humans call Scamander ( $\Sigma \kappa \alpha ́ \mu \alpha v \delta \rho o v)$, for example, should really be called Xanthus ( $\Xi \alpha ́ v \theta o v)$; and even if we call the bird cymindis ( $\kappa \dot{\mu} \mu \mathrm{v} \delta 1 \varsigma)$, the correct and divine name is chalcis $(\chi \alpha \lambda \kappa i \delta \alpha)^{\prime}$.
} 


\section{BIBLIOGRAPHY}

Annas. Julia. 1985. 'Self-Knowledge in Early Plato' in Platonic Investigations. Studies in Philosophy and the History of Philosophy Series. Vol. 13. Edited by Dominic J. O'Meara. Washington DC: Catholic University of America Press.

Brisson, L. 1998. Plato the Myth Maker. Chicago: University of Chicago Press.

Cooper, J.M. and D. S. Hutchinson (eds.). 1997. Plato: Complete Works. Hackett.

Denyer, N. 2001. Plato: Alcibiades. Edited with Introduction and Notes. Cambridge: Cambridge University Press.

Foucault, M. 2005. The Hermeneutics of the Subject: Lectures at the College de France 1981-82. Edited by Frédéric Gros and translated by Graham Burchell. New York: Palgrave MacMillan.

Gerson, L. P. 2002. Knowing Persons. A Study in Plato. Oxford: OUP 2002.

Gordon, J. 2003. 'Eros and Philosophical Seduction in Alcibiades I'. Ancient Philosophy 23.

Johnson, D.M. 1999. 'God as the True Self: Plato’s Alcibiades I', Ancient Philosophy 19.

Lamb, W. R. M. 1927. Charmides. Alcibiades I and II. Hipparchus. The Lovers. Theages. Minos. Epinomis. Plato Volume XII. Loeb Classical Library 201.

McCabe. M. M. 1994. Plato’s Individuals. Princeton: Princeton University.

Pettersson, Olof. 2018. 'The Science of Philosophy: Discourse and Deception in Plato's Sophist' Epoché 22(2): 221-237.

Pradeau, J-F. 1999. 'Introduction', in Platon. Alcibiade. Introduction, notes, bibliography \& index by Pradeau. Translation by C. Marboeuf and J-F. Pradeau. Paris: Flammarion.

Remes, P. 2013. 'Reason to Care: The Object and Structure of Self-Knowledge in the Alcibiades I'. Apeiron 46(3): 270-301. 
Sedley, D. 2003. Plato's Cratylus. New York: Cambridge University Press.

Smith. N.D. 2004. 'Did Plato Write the 'Alcibiades I?'’. Apeiron (37) 2, 93-108. 